\title{
Simple sequence repeat-based diversity in elite pigeonpea genotypes for developing mapping populations to map resistance to Fusarium wilt and sterility mosaic disease
}

\author{
R. K. Saxena ${ }^{1}$, K. B. Saxena ${ }^{2}$, R. V. Kumar ${ }^{2}$, D. A. Hoisington ${ }^{1}$ and R. K. Varshney ${ }^{1,3,4}$ \\ ${ }^{1}$ Centre of Excellence in Genomics (CEG), International Crops Research Institute for the Semi-Arid Tropics (ICRISAT), \\ Patancheru, Greater Hyderabad- 502324, AP, India; ${ }^{2}$ Global Theme - Crop Improvement, International Crops Research \\ Institute for the Semi-Arid Tropics (ICRISAT), Patancheru, Greater Hyderabad- 502324, AP, India; ${ }^{3}$ Genomics towards Gene \\ Discovery Sub-Programme, Generation Challenge Programme (GCP), c/o CIMMYT, Int APDO Postal 6-641, 06600 Mexico \\ DF, Mexico; ${ }^{4}$ Corresponding author. E-mail: r.k.varshney@cgiar.org \\ With 1 figure and 3 tables
}

Received January 13, 2009/Accepted June 26, 2009

Communicated by W. Swiecicki

\begin{abstract}
In order to maximize polymorphism in the mapping populations for mapping loci for Fusarium wilt (FW) and sterility mosaic disease (SMD) resistance in pigeonpea, a set of 32 pigeonpea lines were screened for polymorphism with 30 microsatellite or simple sequence repeat markers. A total of 23 marker loci showed polymorphism with 2-4 alleles and the polymorphism information content for these markers ranged from 0.12 to 0.65 with an average of 0.43 per marker. High number of polymorphic markers, higher genetic dissimilarity coefficient and contrasting phenotypic data taken into consideration and five parental combinations were identified and crosses initiated for developing five genetically diverse mapping populations. Of these crosses, one cross segregates for FW resistance, two for SMD resistance and the remaining two crosses segregate for resistance to both FW and SMD. Development of mapping populations is in progress for mapping loci for resistance to FW and SMD in pigeonpea.
\end{abstract}

Key words: microsatellite markers — diversity - mapping population — Fusarium wilt — sterility mosaic disease

Pigeonpea [Cajanus cajan (L) Mill sp.] is an important grain legume crop of rainfed agriculture in the semi-arid tropics. The Indian sub-continent, Eastern Africa and Central America are the three major pigeonpea producing regions in the world. Although the crop is quite drought tolerant, the crop production is severely challenged by several biotic (e.g. Fusarium wilt (FW), sterility mosaic disease and pod borer) and abiotic (e.g. salinity and water-logging) stresses. As the realized yield in a given environment is the product of interaction involving stress factors, varieties and other environmental factors, very low crop productivity in general is achieved.

Fusarium wilt of pigeonpea is a soil borne disease caused by fungus Fusarium udum. The disease can occur at any stage of crop development and collapse the root system. Wilt symptoms usually appear when plants are flowering and podding but some times the symptoms also appear in 1- to 2-months-old plants. Patches of dead plants in the field are the first indication of wilt. The most characteristic symptom is a purple band extending upwards from the base of main stem. The fungus can survive on infected plant debris in the soil for about 3 years. This causes serious yield losses in susceptible cultivars. In India alone, the loss due to this disease has been estimated at US\$ 71 million (Kannaiyan et al. 1984, Reddy et al. 1993).

Sterility mosaic disease (SMD) is another major constraint for pigeonpea production in the Indian-subcontinent and occurs with regularity and under suitable conditions, spreads rapidly, leading to epidemics. Yield losses depend on the growth stage at which infection occurs. This disease is some times referred to as the 'Green Plague' because at flowering time, affected plants are green with excessive vegetative growth but with no flowers or pods (Jones et al. 2004). In assessing the economic importance of various biotic constraints of pigeonpea, SMD causes greater yield losses than any other disease affecting pigeonpea. In India alone in 1984, losses due to SMD were estimated at 205000 tons of grain valued at US\$ 76 million (Kannaiyan et al. 1984).

More recent studies on the economic impact of $\mathrm{FW}$ and SMD are lacking, but the diseases are endemic in the subcontinent and continue to be responsible for greater losses than ever before (Reddy et al. 1998, Zote et al. 1991). Therefore, to minimize yield losses due to SMD and FW, it is necessary to tackle these problems at molecular level by developing cultivars which resist/tolerate these biotic stresses and have greater recovery from the damage. Genomic tools especially molecular markers have facilitated breeding in many cereal crops leading to development of several improved cultivars/varieties with enhanced resistance/tolerance to biotic or abiotic stresses (Varshney et al. 2006).

Molecular markers and genetic maps are the important prerequisites for undertaking molecular breeding methodologies for crop improvement. Among different kind of molecular marker systems available at present, microsatellite or simple sequence repeat (SSR) markers have proven the markers of choice in practical breeding (Gupta and Varshney 2000, Varshney et al. 2005). In case of pigeonpea, although a few SSR markers have become available recently (Burns et al. 2001, Odeny et al. 2007), not a single genetic map is available so far. This can be attributed to mainly two factors: (i) availability of a meagre number of molecular markers and (ii) a very low level of polymorphism in cultivated pigeonpea germplasm (Yang et al. 2006, Odeny et al. 2007). In order to overcome these problems, while a critical set of novel SSR markers are being developed through SSR-enriched libraries 
(Saxena et al. 2009) and BAC (bacterial artificial chromosome)- end sequences at International Crops Research Institute for the Semi-Arid Tropics (ICRISAT) and its collaborating institutes like University of California-Davis (UC-Davis), USA and National Research Centre on Plant Biotechnology (NRCPB), New Delhi, India, there is a need to develop suitable mapping populations that have adequate molecular genetic variation in addition to the contrasting phenotypes for FW and SMD resistance.

With the objective of developing a set of diverse mapping populations of pigeonpea, segregating for FW and SMD resistance, the present study deals with surveying SSR-based molecular diversity in an elite collection of pigeonpea genotypes. Phenotypic data collected for 5 years for FW and SMD resistance on the elite genotypes together with SSR genetic diversity data have been used to select a set of diverse genotypes for developing the useful mapping populations that will enable mapping of FW and SMD and eventually undertaking molecular breeding for these important traits in pigeonpea.

\section{Materials and Methods}

Plant material: A large number of elite pigeonpea lines, that are adapted to different climatic zones and have good agronomic performance, were evaluated for different stresses at Patancheru for 5 years (1300 lines in 2002, 664 lines in 2003, 784 lines in 2004, 1129 lines in 2005 and 997 lines in 2006). Based on phenotypic data for resistance to FW and SMD, finally a set of 32 lines was selected. This set includes 20 resistant and four susceptible genotypes to both FW and SMD (Table 1).

DNA extraction: Two to three young leaves from field grown plants of different pigeonpea genotypes were collected for DNA extraction. DNA was isolated and purified following Cuc et al. (2008). The DNA quantity for each sample was assessed on $0.8 \%$ agarose gel and DNA concentrations were normalized at $5 \mathrm{ng} / \mu \mathrm{l}$.

Polymerase chain reactions (PCR): DNA from an individual plant of each accession was screened with existing set of 30 polymorphic SSR markers (Table 2) at ICRISAT. PCRs were performed in a $5 \mu \mathrm{l}$ reaction volume $\left[0.5 \mu \mathrm{l}\right.$ of $10 \mathrm{x}$ PCR buffer, $0.3 \mu \mathrm{l}$ of $25 \mathrm{mM} \mathrm{MgCl}_{2}$, $0.5 \mu \mathrm{l}$ of $2 \mathrm{mM}$ dNTPs, $0.15 \mu \mathrm{l}$ of $10 \mathrm{pM}$ primer (MWG-Biotech AG, Bangalore, India), $0.3 \mathrm{U}$ of Taq polymerase (Bioline, London, UK) and $1.0 \mu \mathrm{l}(5 \mathrm{ng})$ of template DNA] in 96-well microtiter plate (ABgene, Rockford, IL, USA) using thermal cycler GeneAmp PCR System 9700 (Applied Biosystems, Foster City, CA, USA). A touch down PCR programme was used to amplify the DNA fragments: the initial denaturation was for $3 \mathrm{~min}$ at $95^{\circ} \mathrm{C}$. This was followed by initial 10 cycles of denaturation for $20 \mathrm{~s}$ at $94^{\circ} \mathrm{C}$, annealing for $20 \mathrm{~s}$ at $55^{\circ} \mathrm{C}$ (the annealing temperature for each cycle being reduced by $1^{\circ} \mathrm{C}$ per cycle) and extension for $30 \mathrm{~s}$ at $72^{\circ} \mathrm{C}$. Subsequently, 35 cycles of denaturation at $94^{\circ} \mathrm{C}$ for $20 \mathrm{~s}$, annealing for $20 \mathrm{~s}$ at $48^{\circ} \mathrm{C}$ and extension for $30 \mathrm{~s}$ at $72^{\circ} \mathrm{C}$ were used and followed by $20 \mathrm{~min}$ final extension at $72^{\circ} \mathrm{C}$. The PCR amplification products were separated on a $6 \%$ polyacrylamide gel and visualized by silver staining.

SSR data scoring and analysis: The profile produced by SSR markers were scored manually: each allele was scored as present (1) or absent (0) for each of the SSR loci. 0-1 matrix was subjected to similarity analysis based on Jaccard's index (Jaccard 1908), to derive a matrix of similarity coefficient. Pairwise comparisons from the similarity matrix were used to generate a dendrogram of genetic relatedness using NTSYSpc program (Rolf 1997).

The term polymorphic information content (PIC) was originally introduced into human genetics by Botstein et al. (1980). It refers to the value of a marker for detecting polymorphism within a population, depending on the number of detectable alleles and the distribution of their frequency. In the present study, PIC value of a marker was calculated as follows (Anderson et al. 1993)

$$
\mathrm{PIC}=1-\sum_{\mathrm{i}=1}^{k} P_{i}^{2}
$$

where $k$ is the total number of alleles detected for a given marker locus and $P_{i}$ is the frequency of the $i$ th allele in the set of genotypes investigated.

\section{Results}

\section{Phenotyping of germplasm lines for FW and SMD}

The disease reaction of a larger number of genotypes was assessed for the successive 5 years (2002-2006) in the wilt-sick plot for pigeonpea, maintained at ICRISAT. Leaf stapling technique was used for rapid screening of pigeonpea genotypes against SMD (Nene et al. 1990), wherein infected leaflets carrying mites aid in virus transmission on to the healthy plants. Individual plants of each genotype were scored for disease incidence (in \%) at the seedling, mid- and late- plant development stages of the crop. The reaction of individual plants was recorded based on typical wilt and SMD symptoms. A genotype was considered as resistant if it did not show any symptom of the disease (0-10\% disease incidence), as susceptible if it showed the symptoms at any stage of the crop and with $>20 \%$ disease incidence. The genotype showing disease incidence between $10-20 \%$ was considered as moderate resistant. By using these criteria, for $\mathrm{FW}$, at least 21 lines showed moderate to strong resistance for 5 years, while nine lines always showed susceptibility (Table 1). Similarly for SMD, 23 lines showed moderate to strong resistance for all 5 years and seven lines consistently showed susceptibility.

\section{Marker polymorphism}

In addition to 30 published SSR markers (Burns et al. 2001, Odeny et al. 2007), about 134 new SSR markers have been developed at ICRISAT by using SSR enriched genomic DNA libraries (Saxena et al. 2009). Based on initial screening of all 164 SSR markers on two genotypes (i.e. ICP 28 and ICPW 94) in a separate study, a set of 30 most informative markers with high PIC value and high quality marker profiling pattern was identified. Screening of these 30 SSR markers on 32 accessions provided polymorphism with $23(71.2 \%)$ markers (Table 2$)$. These markers revealed 2 (CCB1, CCB4, CCac012, CCac013, CCat011, CCttc003, CCtc004, CCttc007, CCttc018 and PKS31) to 4 (CCtc012 and CCttc006) alleles with an average of 2.7 alleles per marker and yielded a total of 61 alleles. The PIC value for these markers ranged from 0.12 (PKS31) to 0.65 (CCB10) with an average of 0.43 per marker in the genotypes examined.

To understand the possible relationship between polymorphism of SSR markers with repeat unit length of the corresponding SSRs, two scatter plots were made between repeat unit length and number of alleles detected and the PIC value calculated (data not shown). These analyses did not show a correlation between repeat unit length and number of alleles/PIC value. However there were some indications that the SSR markers having 7-13 repeat units yield more alleles and the markers having $4-15$ repeat units display a high PIC value $(>0.50)$. 
Table 1: List of pigeonpea genotypes with phenotyping data for Fusarium wilt (FW) and sterility mosaic disease (SMD) for 5 years

\begin{tabular}{|c|c|c|c|c|c|c|c|c|c|c|}
\hline & \multicolumn{5}{|c|}{ 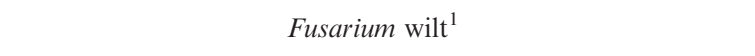 } & \multicolumn{5}{|c|}{ Sterility mosaic disease ${ }^{1}$} \\
\hline & 2006 & 2005 & 2004 & 2003 & 2002 & 2006 & 2005 & 2004 & 2003 & 2002 \\
\hline \multicolumn{11}{|c|}{ Resistant to both FW and SMD } \\
\hline ICP 7035 & $4(57)$ & $0(16)$ & $29(45)$ & $7(330)$ & $24(17)$ & $0(57)$ & $0(16)$ & $0(45)$ & $0(330)$ & $0(17)$ \\
\hline ICPB 2043 & $7(60)$ & $0(80)$ & $14(7)$ & NA & NA & $0(60)$ & $1(80)$ & $14(7)$ & NA & NA \\
\hline ICPL 20096 & $0(23)$ & $8(52)$ & $0(26)$ & $0(73)$ & 0 (19) & $17(43)$ & $0(52)$ & $0(26)$ & $0(73)$ & 0 (19) \\
\hline ICPL 20097 & $2(45)$ & $0(50)$ & $14(21)$ & $0(60)$ & $0(18)$ & $0(45)$ & $3(50)$ & $14(21)$ & $0(60)$ & $0(18)$ \\
\hline ICPL 20098 & $0(28)$ & $2(47)$ & $0(21)$ & $0(42)$ & 0 (18) & $0(28)$ & $0(47)$ & $0(21)$ & $0(42)$ & $0(18)$ \\
\hline ICPL 20099 & $0(24)$ & $0(62)$ & $0(20)$ & $2(51)$ & 0 (19) & $0(24)$ & $0(62)$ & $0(20)$ & $0(51)$ & 0 (19) \\
\hline ICPL 20108 & $0(23)$ & $3(64)$ & $1.8(44)$ & $1.9(51)$ & $15(20)$ & $0(23)$ & $5(64)$ & $2(44)$ & $0(51)$ & $0(20)$ \\
\hline ICPL 20110 & $0(12)$ & $4(69)$ & $0(46)$ & $1.6(62)$ & $0(15)$ & 0 (12) & $0(69)$ & $0(46)$ & $0(62)$ & $0(15)$ \\
\hline ICPL 20112 & $1(15)$ & $11(71)$ & $27(45)$ & $0(51)$ & $0(10)$ & $7(7)$ & $0(71)$ & $27(45)$ & $0(51)$ & $0(10)$ \\
\hline ICPL 20113 & $4(52)$ & $0(62)$ & $0(44)$ & $0(37)$ & $0(8)$ & $0(52)$ & $0(62)$ & $0(44)$ & $0(37)$ & $0(8)$ \\
\hline ICPL 20125 & $0(16)$ & $7(71)$ & $0(42)$ & $0(49)$ & $5(22)$ & $0(16)$ & $0(71)$ & $0(42)$ & 0 (49) & $0(22)$ \\
\hline ICPL 20127 & $14(14)$ & $4(51)$ & $9(21)$ & $0(50)$ & 0 (14) & 7 (14) & $0(51)$ & $9(21)$ & $0(50)$ & $0(14)$ \\
\hline ICPL 20129 & $0(56)$ & $0(70)$ & $4(46)$ & $0(34)$ & $11(9)$ & $2(56)$ & $0(70)$ & $4(46)$ & $0(34)$ & $0(9)$ \\
\hline ICPL 20135 & $4(49)$ & $2(47)$ & $8.3(49)$ & $0(59)$ & $22(18)$ & $2(49)$ & $0(47)$ & 0 (49) & $0(59)$ & $0(18)$ \\
\hline ICPL 87051 & NA & 4 (114) & $31(384)$ & $1.9(102)$ & $10(60)$ & NA & $9(114)$ & $4(384)$ & 0 (102) & $0(60)$ \\
\hline ICPL 87119 & $0(23)$ & $0(56)$ & $0(25)$ & $1.8(106)$ & $1(30)$ & $9(23)$ & $0(56)$ & $0(25)$ & $0(106)$ & $1(30)$ \\
\hline ICPL 96053 & $0(16)$ & $0(32)$ & $5(22)$ & $0(71)$ & $5(51)$ & $0(16)$ & $0(32)$ & $5(22)$ & $0(71)$ & $0(51)$ \\
\hline ICPL 96058 & NA & $0(38)$ & $12(408)$ & $1.7(115)$ & 7 (159) & $9(79)$ & $0(38)$ & $1(408)$ & $0(115)$ & $0(159)$ \\
\hline ICPL 99050 & $11(56)$ & $0(26)$ & $0(23)$ & $1.8(109)$ & $3(55)$ & $4(56)$ & $0(26)$ & $0(23)$ & 0 (109) & $0(55)$ \\
\hline ICPL 99052 & $6(78)$ & $11(18)$ & $0(21)$ & NA & NA & $8(78)$ & $6(18)$ & $0(21)$ & NA & NA \\
\hline \multicolumn{11}{|c|}{ Susceptible to both FW and SMD } \\
\hline ICPB 2042 & $49(61)$ & $45(11)$ & $93(27)$ & NA & NA & $13(61)$ & $45(11)$ & $22(27)$ & NA & NA \\
\hline ICPB 2051 & $97(100)$ & $67(18)$ & $100(26)$ & NA & NA & $13(100)$ & $28(18)$ & $19(26)$ & NA & NA \\
\hline ICPL 332 & $100(18)$ & $81(58)$ & $83.8(52)$ & NA & NA & $22(18)$ & $72(58)$ & $71.1(52)$ & NA & NA \\
\hline ICPL 87091 & $95(21)$ & $67(21)$ & $40.9(22)$ & $13(32)$ & NA & $33(21)$ & $37(21)$ & $45.4(22)$ & $28(32)$ & NA \\
\hline \multicolumn{11}{|c|}{ Resistant to SMD and susceptible to FW } \\
\hline ICP 2376 & $100(37)$ & $98(41)$ & $100(40)$ & $73.8(42)$ & $75(40)$ & $0(37)$ & $0(100)$ & $0(40)$ & $0(42)$ & $0(40)$ \\
\hline ICPB 2049 & $87(61)$ & $58(19)$ & $100(20)$ & NA & NA & $0(61)$ & $0(19)$ & $0(20)$ & NA & NA \\
\hline ICPL 85063 & NA & $19(131)$ & NA & $58.1(421)$ & NA & NA & $0(31)$ & NA & $1.9(421)$ & NA \\
\hline \multicolumn{11}{|c|}{ Resistant to FW and susceptible to SMD } \\
\hline ICP 8863 & $0(16)$ & $6(66)$ & $0(58)$ & $0(20)$ & $0(25)$ & $81(16)$ & $83(66)$ & $98(58)$ & $71.4(20)$ & $100(25)$ \\
\hline \multicolumn{11}{|l|}{ Other lines } \\
\hline ICPL 84023 & NA & NA & $53(40)$ & NA & NA & NA & NA & $23(40)$ & NA & NA \\
\hline ICPL 86012 & NA & $9(38)$ & $57(21)$ & NA & NA & NA & $8(38)$ & $0(21)$ & NA & NA \\
\hline ICPL 88034 & $73(34)$ & $71(30)$ & $95(60)$ & $83(15)$ & $36(20)$ & $33(34)$ & $14(30)$ & $63(60)$ & $0(15)$ & $0(20)$ \\
\hline ICPL 88039 & $100(22)$ & $67(32)$ & $94(40)$ & $65(25)$ & $71(21)$ & $34(22)$ & $27(32)$ & $78(40)$ & $75(25)$ & $14(21)$ \\
\hline
\end{tabular}

${ }^{1}$ Disease score $=$ Susceptibility $\%$, Values in parenthesis represent total plant population.

NA, Data not available. Resistant $=0-10 \%$; Moderate resistant $=10-20 \%$; Susceptible $=>20 \%$.

\section{Genetic diversity}

Genotyping data obtained for 61 alleles detected at 23 loci were used for calculating genetic similarity (GS) in pairwise combinations among all the genotypes. The GS index ranged from 0.20 to 0.81 with an average of 0.50 among the genotypes examined. The highest genetic similarity (GS $=0.81$ ) was observed between ICPL 87051 and ICPL 86012 while the ICPL 87119 and ICPB 2043 showed the lowest genetic similarity $(\mathrm{GS}=0.20$ ).

In order to understand the relationships among the genotypes, genetic similarity matrix was used to prepare the unweighted pair group method with arithmetic mean (UPGMA)-based phenogram (Fig. 1). All the 32 genotypes could be distinguished by 23 SSR markers. The phenogram classified all the genotypes in two main clusters. While cluster ' $A$ ' contained three genotypes, the cluster ' $B$ ' contained the remaining 29 genotypes. It is interesting to note that all three genotypes falling in cluster 'A' were resistant genotypes (ICPL 87119, ICPL 96053 and ICPL 20097) for both FW and SMD. The cluster ' $\mathrm{B}$ ' could be classified into two sub-clusters, namely 'B I' containing three genotypes (ICPB 2043, ICPL 85063 and ICPL 99052) and 'B II' containing the remaining 26 genotypes. The cluster 'B II' contained all seven genotypes (ICPB 2051, ICPL 87091, ICPL 86012, ICPL 84023, ICPB 2042, ICPB 2049 and ICPL 332) susceptible to both FW and SMD and 17 genotypes resistant to both FW and SMD. In addition, two more genotypes (resistant to FW and susceptible to SMD or vice versa) were grouped in cluster 'B II'.

\section{Selection of putative lines for developing mapping population}

As the final objective of this study was to select the most diverse parental combination(s) for developing the mapping populations segregating for FW and SMD resistance, the marker polymorphism data were analysed together with the genetic dissimilarity and phenotypic data. While selecting the potential parental combinations for developing the most informative mapping populations, following three criteria were used: (i) high number of polymorphic markers, (ii) higher genetic dissimilarity coefficient, and (iii) high phenotypic variation. However, it is very difficult if not impossible to identify the parental combinations that have higher values for all the above parameters. In such cases, more weightage was given to marker polymorphism data.

For FW as well as SMD, all pairwise genotype combinations were checked for all three parameters mentioned above. While one parental combination was identified for FW resistance alone (Table 3), two parental combinations were identified for SMD resistance alone (Table 3). As some 


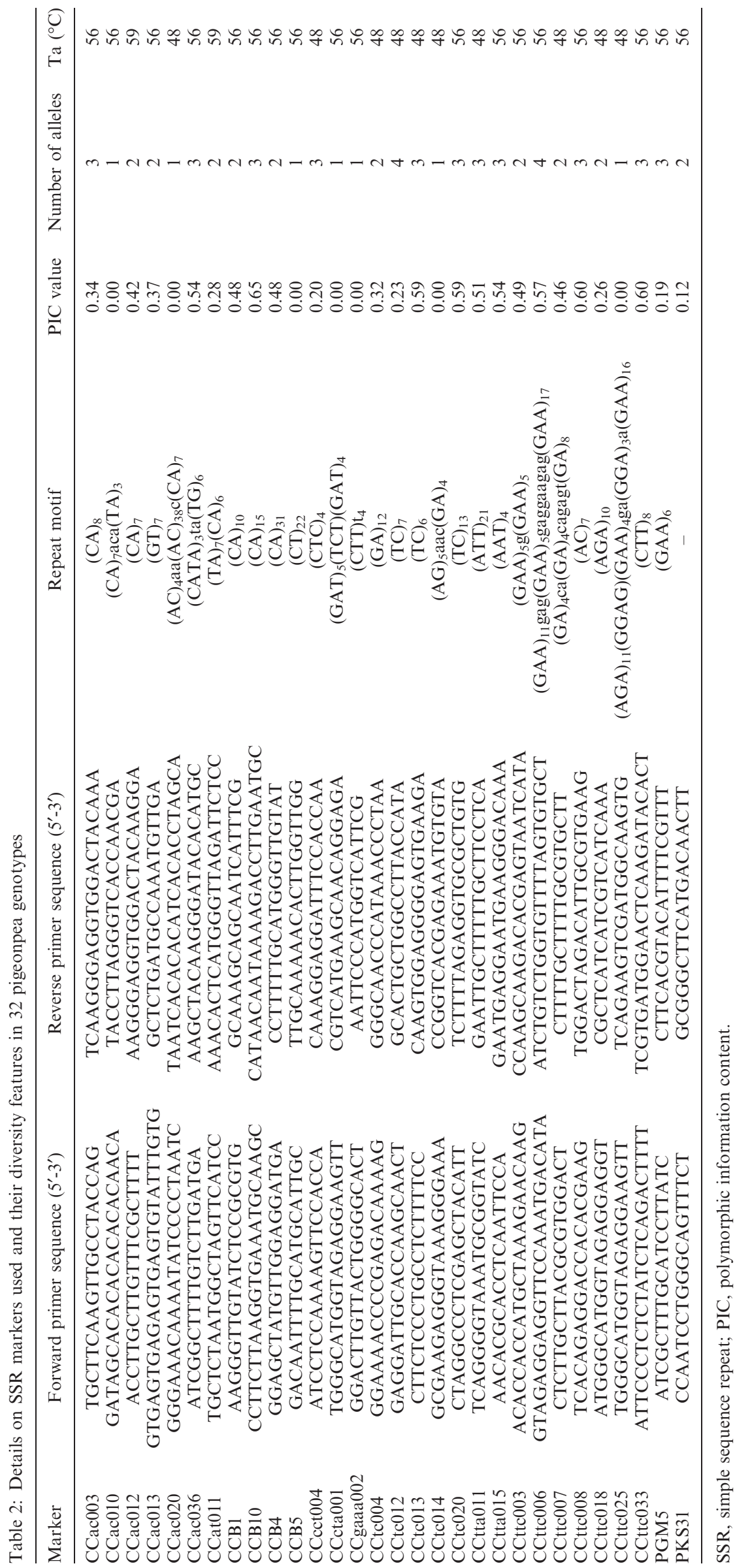




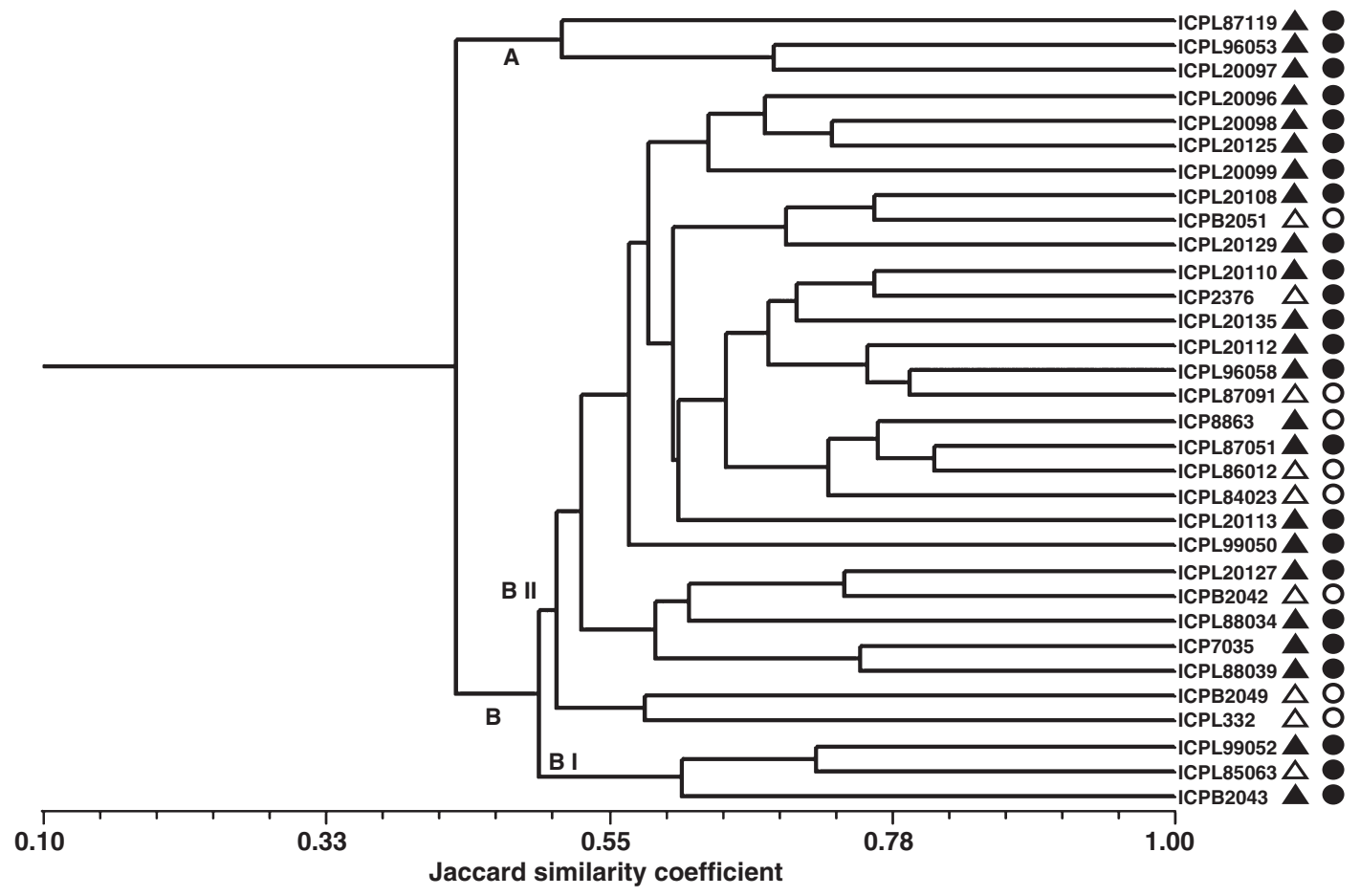

Fig. 1: Genetic relationships among 32 genotypes based on the analyses of 23 simple sequence repeat markers. $\mathbf{\Delta}$ Fusarium wilt resistant, $\triangle$ Fusarium wilt susceptible, 0 Sterility mosaic disease resistant, $\bigcirc$ Sterility mosaic disease susceptible

Table 3: Parental genotypes selected for developing mapping populations segregating for Fusarium wilt (FW) and sterility mosaic disease (SMD)

\begin{tabular}{|c|c|c|c|c|c|c|c|c|c|c|c|c|}
\hline \multirow{2}{*}{$\begin{array}{l}\text { Parental } \\
\text { genotype }\end{array}$} & \multicolumn{5}{|c|}{$\begin{array}{l}\text { Disease score } \\
\text { for Fusarium wilt }{ }^{1}\end{array}$} & \multicolumn{5}{|c|}{$\begin{array}{l}\text { Disease score } \\
\text { for sterility mosaic }\end{array}$} & \multirow{2}{*}{$\begin{array}{l}\text { Dis-similarity } \\
\text { index }\end{array}$} & \multirow{2}{*}{$\begin{array}{c}\text { Number of } \\
\text { polymorphic } \\
\text { markers }\end{array}$} \\
\hline & 2006 & 2005 & 2004 & 2003 & 2002 & 2006 & 2005 & 2004 & 2003 & 2002 & & \\
\hline \multicolumn{13}{|c|}{ Parental combination for FW mapping population } \\
\hline ICPB 2049 & $87(61)$ & $58(19)$ & $100(20)$ & NA & NA & - & - & - & - & - & 0.62 & 14 \\
\hline ICPL 99050 & $11(56)$ & $0(26)$ & $0(23)$ & $1.8(109)$ & $3(55)$ & - & - & - & - & - & & \\
\hline \multicolumn{13}{|c|}{ Parental combination for SMD mapping population } \\
\hline ICP 8863 & - & - & - & - & - & $35(17)$ & $83(66)$ & $98(58)$ & $71.4(20)$ & $100(25)$ & 0.71 & 15 \\
\hline ICPL 20097 & - & - & - & - & - & $0(45)$ & $3(50)$ & $14(21)$ & $0(60)$ & $0(18)$ & & \\
\hline ICPL 332 & - & - & - & - & - & $22(18)$ & $72(28)$ & $71.1(52)$ & NA & NA & 0.64 & 13 \\
\hline ICP 7035 & - & - & - & - & - & $0(57)$ & $0(16)$ & $29(45)$ & $0(12)$ & $0(17)$ & & \\
\hline \multicolumn{13}{|c|}{ Parental combination for both FW and SMD mapping population } \\
\hline ICPL 332 & $100(18)$ & $81(58)$ & $83.8(52)$ & NA & NA & $22(18)$ & $72(28)$ & $71.1(52)$ & NA & NA & 0.62 & 14 \\
\hline ICPL 20096 & $0(23)$ & $8(52)$ & $0(26)$ & $0(73)$ & 0 (19) & $17(43)$ & $0(52)$ & $0(26)$ & $0(73)$ & 0 (19) & & \\
\hline ICPL 87091 & $95(21)$ & $67(21)$ & 40.9 (22) & $13(32)$ & NA & $33(21)$ & $37(21)$ & $45.4(22)$ & $28(32)$ & NA & 0.62 & 13 \\
\hline ICPL 87119 & $0(23)$ & $0(56)$ & $0(25)$ & $1.8(106)$ & $1(30)$ & $9(23)$ & $0(56)$ & $0(25)$ & $0(106)$ & $1(30)$ & & \\
\hline
\end{tabular}

${ }^{1}$ Disease score $=$ Susceptibility $\%$, Values in parenthesis represent total plant population.

NA, Data not available.

genotypes showed resistance as well as susceptibility to both FW and SMD, two parental combinations were selected that showed variation for FW and SMD resistance (Table 3). In total, five parental combinations were selected for developing the mapping populations.

\section{Discussion}

The most important step in a breeding programme is the choice of parents with good performance and wide genetic base. Thus measures of the genetic divergence, ahead of making any cross, may help breeders to concentrate their efforts only on most promising combinations. However, most of the times, many breeders develop the mapping populations just based on phenotypic data without caring of the adequate amount of genetic diversity between the parental genotypes. Indeed, there have been several cases where screening of parental genotypes of the mapping populations provided no/ very low polymorphism and populations were already advanced to recombinant inbred line stage (Chandra et al. 2004, Odeny 2006).

Phenotyping undertaken on elite pigeonpea genotypes for their reaction to FW and SMD identified 21 resistant lines to FW and 23 resistant lines to SMD including 20 lines resistant to both FW and SMD. As both these diseases lead to severe production constraints, these resistant genotypes will be useful for pigeonpea breeding aimed at developing resistant varieties. To develop the diverse mapping populations, in addition to 
contrasting phenotypic data, it is important to select the parental genotypes based on genetic diversity as well. The present study therefore employs the phenotypic data of selected elite pigeonpea lines for resistance to FW and SMD diseases as well as genotyping data with SSR markers. Phenotypic data compiled for five consecutive years (20022006) showed good variation for resistance to FW and SMD, which allowed identification of several resistant or susceptible lines to one of the two or both the diseases. Resistant lines to one or both disease should be very useful to introgress the resistance to $\mathrm{FW}$ and/or SMD while developing superior pigeonpea varieties through classical breeding as well.

Marker genotyping of these elite lines, however, showed low level of genetic variation. Several earlier studies using SSR, AFLP and Diversity Array Technologies (DArT) markers also indicated a narrow genetic diversity in cultivated genepool of pigeonpea (Burns et al. 2001, Panguluri et al. 2006, Yang et al. 2006, Odeny et al. 2007). As compared to earlier SSR-based diversity studies in pigeonpea (Burns et al. 2001, Odeny et al. 2007), a higher level of polymorphism was observed in the present study that can be attributed to the use of selected highly polymorphic markers. While comparing the SSR polymorphism e.g. allele numbers and PIC values with the repeat units, no consistent relationship was observed (data not shown). In some earlier studies in different plant species, a positive correlation has been shown between degree of polymorphism and repeat unit length (Moretzsohn et al. 2005, Weber 1990) while some other studies reported either no or weak relationship between SSR polymorphism and repeat unit length (Ferguson et al. 2004, He et al. 2003, Cuc et al. 2008).

In terms of cluster analysis based on UPGMA-dendrogram, mainly two clusters were observed that could be divided further into sub-clusters. Grouping of three genotypes (i.e. ICPL 87119, ICPL 96053 and ICPL 20097) that are resistant to both FW and SMD in one major cluster (cluster 'A') indicates introgression of FW and SMD resistance in these genotypes from the same or similar ancestor. Several subclusters on the other hand contained resistant and susceptible genotypes together as well. Therefore, it will be interesting to understand the inheritance/genetics of resistance to FW and SMD. It is also important to note that in the UPGMA phenogram. Cluster BII contained resistant and susceptible genotypes could not be distinguished very clearly. Higher resolution in such clusters may be possible if larger number of markers are used for diversity analysis.

Based on marker polymorphism data i.e. allele numbers and PIC values and cluster analysis and earlier diversity studies involving AFLP (Panguluri et al. 2006), SSRs (Odeny et al. 2007) and DArT (Yang et al. 2006) analyses, it can be generalized that genetic diversity in pigeonpea genepool is low. However, one should recognize here that all the above studies employed a limited number of molecular markers. It is also possible that currently available marker systems (that have been used so far) may not be sensitive enough to detect narrow genetic diversity. For instance, single base polymorphism in intronic region, if any, present in the pigeonpea genome could be skipped majority of times when germplasm was analysed with SSR, AFLP or DArT markers. Higher DNA polymorphisms can be detected in pigeonpea; if a critical mass of molecular markers e.g. SSR markers in thousand numbers or better marker systems such as single nucleotide polymorphisms (SNPs) are developed. Such efforts are indeed underway at ICRISAT and several other collaborating institutes such as
UC-Davis, USA (DR Cook, personal communication), NRCPB, India (NK Singh, personal communication) and National Centre for Genome Resources (NCGR), USA (GD May, personal communication).

For developing the diverse mapping populations to map FW and SMD resistance, parental genotypes were selected based on marker genotyping data i.e. high number of polymorphic markers and higher genetic dissimilarity coefficient and phenotypic data (high diversity). By using these criteria, as much as it could be possible, one parental combination (ICPB $2049 \times$ ICPL 99050) was identified for FW resistance alone, two parental combinations (ICP $8863 \times$ ICPL 20097 and ICPL $332 \times$ ICP 7035) for SMD resistance alone and two parental combinations (ICPL $332 \times$ ICPL 20096 and ICPL $87091 \times$ ICPL 87119) were selected that showed variation for both FW and SMD resistance. Five parental combinations, selected in this way, were used for crossing and the development of mapping populations is in progress.

In summary, the present study reports genetic diversity of 32 selected breeding lines, resistant/susceptible to FW and SMD, with 30 informative SSR markers. Based on genetic diversity and trait phenotypic data, five parental combinations were selected to develop diverse mapping populations so that good genetic and QTL maps can be developed in pigeonpea. Such an approach should prove useful in species like pigeonpea where no genetic map is available at present and the species suffers from low genetic diversity in the cultivated breeding lines. Based on this study, we recommend the selection of genotypes for making the crosses using genetic distance data estimated on the basis of molecular markers and also phenotypic data. It is also important to consider the maturity period as well while selecting the potential parental combinations.

\section{Acknowledgements}

Authors are thankful to the Indian Pigeonpea Genomics Initiative of Indian Council of Agricultural Research (ICAR), New Delhi, Government of India under Indo-US Agricultural Knowledge Initiative (AKI) and Generation Challenge Programme (GCP) of Consultative Group on International Agricultural Research (CGIAR) Thanks are also due to Mr. Gafoor, Mr. Rama Rao and Mr. Pentaiah for technical assistance.

\section{References}

Anderson, J. A., G. A. Churchill, J. E. Sutrique, S. D. Tanksley, and M. E. Sorrells, 1993: Optimizing parental selection for genetic linkage maps. Genome 36, 181-186.

Botstein, D., R. L. White, M. Skolnick, and R. W. Davis, 1980: Construction of a genetic linkage map in man using restriction fragment length polymorphism. Am. J. Hum. Genet. 32, 314-331.

Burns, M. J., K. J. Edwards, H. J. Newbury, B. V. Ford-Lloyd, and C. D. Baggott, 2001: Development of simple sequence repeat (SSR) markers for the assessment of gene flow and genetic diversity in pigeonpea (Cajanus cajan). Mol. Ecol. Notes 1, 283-285.

Chandra, S., H. K. Buhariwalla, J. Kashiwagi, S. Harikrishna, K. Rupa Sridevi, L. Krishnamurthy, R. Serraj, and J. H. Crouch, 2004: Identifying QTL-linked Markers in marker-deficient Crops. New directions for a diverse planet: Proceedings of the 4th International Crop Science Congress. Brisbane, Australia, 26 Sep - 1 Oct.

Cuc, L. M., E. S. Mace, J. H. Crouch, V. D. Quang, T. D. Long, and R. K. Varshney, 2008: Isolation and characterization of novel microsatellite markers and their application for diversity assessment in cultivated groundnut (Arachis hypogaea). BMC Plant Biol. 8, 55. 
Ferguson, M. E., M. D. Burow, S. R. Schultz, P. J. Bramel, A. H Paterson, S. Kresovich, and S. Mitchell, 2004: Microsatellite identification and characterization in peanut ( $A$. hypogaea L.). Theor. Appl. Genet. 108, $1064-1070$.

Gupta, P. K., and R. K. Varshney, 2000: The development and use of microsatellite markers for genetic analysis and plant breeding with emphasis on bread wheat. Euphytica 113, 163-185.

He, G., R. Meng, M. Newman, G. M. Gao, R. N. Pittman, and C. S Prakash, 2003: Microsetellites as DNA markers in cultivated peanut (Arachis hypogaea L.). BMC Plant Biol. 3, 3.

Jaccard, P., 1908: Nouvelles recherches sur la distribution florale. Bull. Soc. Vaudoise Sci. Nat. 44, 223-270.

Jones, T. A., P. Kumar Lava, K. B. Saxena, N. K. Kulkarni, V. Muniyappa, and F. Waliyar, 2004: Sterility mosaic disease the 'Green Plague' of pigeonpea. Plant Dis. 88, 436 - 445.

Kannaiyan, J., Y. L. Nene, M. V. Reddy, J. G. Ryan, and T. N. Raju, 1984: Prevalence of pigeonpea disease and associated crop losses in Asia, Africa and America. Trop. Pest Manag. 30, 62-71.

Moretzsohn, M. C., L. Leoi, K. Proite, P. M. Guimaraes, S. C. M. Leal-Bertioli, M. A. Gimanes, W. S. Martin, J. F. M. Valls, D. Grattapaglia, and D. Bertioli, 2005: A microsatellite - based, gene-rich linkage map for the AA genome of Arachis (Fabaceae) Theor. Appl. Genet. 111, 1060-1071.

Nene, Y. L., S. D. Hall, and V. K. Sheila, 1990: The pigeonpea. CAB International, Wallingord, UK.

Odeny, D. A., 2006: Microsatellite Development and Application in Pigeonpea (Cajanus cajan (L.) Millsp.). PhD dissertation. Universität Bonn, Germany.

Odeny, D. A., B. Jayashree, M. Ferguson, D. Hoisington, J. Crouch, and C. Gebhardt, 2007: Development, characterization and utilization of microsatellite markers in pigeonpea. Plant Breed. 126, $130-137$.
Panguluri, S. K., K. Janaiah, J. N. Govil, P. A. Kumar, and P. C. Sharma, 2006: AFLP fingerprinting in pigeonpea (Cajanus cajan (L.) Millsp.) and its wild relatives. Genet. Resour. Crop Evol. 53, $523-531$.

Reddy, M. V., T. N. Raju, S. B. Sharma, Y. L. Nene, and D. McDonald, 1993: Handbook of Pigeonpea Diseases. Information bulletin no. 42, ICRISAT, Hyderabad, India (ISBN 92-9066277-8).

Reddy, M. V., T. N. Raju, and J. M. Lenne, 1998: Diseases of Pigeonpea. In: D. J. Allen, and J. M. Lenne (eds), The Pathology of Food and Pasture Legumes, 517-558. CAB International, Wallingford, UK.

Rolf, J. F., 1997: NTSYSpc. Numerical taxonomy and multivariate analysis system. Version 2.00 Exeter Software. Setauket, NY, USA.

Saxena, R. K., C. Prathima, K. B. Saxena, D. Hoisington, N. K. Singh, and R. K. Varshney, 2009: Novel SSR markers for polymorphism detection in pigeonpea (Cajanus spp.). Plant Breed. doi: 10.1111/j.1439-0523.2009.01680.x.

Varshney, R. K., A. Graner, and M. E. Sorrells, 2005: Genic microsatellite markers in plants: features and applications. Trends Biotechnol. 23, 48-55.

Varshney, R. K., D. A. Hoisington, and A. K. Tyagi, 2006: Advances in cereal genomics and applications in crop breeding. Trends Biotechnol. 24, 490- 499.

Weber, J. L., 1990: Informativeness of human (cC-dA)n (dG-dT)n polymorphisms. Genomics 7, 524-530.

Yang, S., W. Pang, G. Ash, J. Harper, J. Carling, P. Wenzl, E. Huttner, X. Zong, and A. Kilian, 2006: Low level of genetic diversity in cultivated pigeonpea compared to its wild relatives is revealed by diversity arrays technology. Theor. Appl. Genet. 113, 585-595.

Zote, K. K., V. R. Mali, C. D. Mayee, S. V. Kulkarni, and T. S. Mote, 1991: Outbreak of sterility mosaic of pigeonpea in Marathwada region of Maharashtra, India. Int. Pigeonpea News Lett. 14, 19-21. 